\title{
Analysis of Micro-texture Geometrical Deviations in Wet Chemical Machining
}

\author{
S. Gandhi ${ }^{1 *}$, R. Chanmanwar ${ }^{2}$, S. Sapkal ${ }^{3}$ \\ ${ }^{1}$ PG Student, ${ }^{2}$ Assistant Professor, ${ }^{3}$ Associate Professor \\ Walchand College of Engineering, Sangli, India \\ \{sarvadnyagandhi363@gmail.com\}
}

\begin{abstract}
The recent development in manufacturing sector has brought the world closer. The development in manufacturing techniques is due to advancement in material sciences for getting better quality of tool and secondly utilization of alternate energy sources. Wet chemical machining process is a non-traditional method to produce the complex and complicated shapes on the flat and thin sheets which basically is a controlled corrosion phenomenon, the economical and precision capability of the technique is making it a feasible alternative for other machining techniques. The Wet chemical etching process has been developed based upon the technique used similarly in electronic industries to manufacture printed circuit boards. The paper deals with the experiments conducted to analyse the deviation in geometrical features of micro- textures in flexure bearing and optical encoders.
\end{abstract}

Keywords: Wet chemical etching, geometrical deviation, optical encoder, flexure bearing

\section{Introduction}

In recent times, scope and utilization of Micro/Nano devices is increasing due to advancement and emerging technologies. Their advantages over macro counterparts is because of their low cost, compact size, less energy consumption, less material requirement and rapid response time. Increased challenge among the manufacturers to produce the high quality products and meet the customer satisfaction is also due to this advancement. The drawbacks of traditional machining methods are overcome by non-traditional machining and founds more advantageous. Micro Electro Mechanical Systems (MEMS), micro-ECD, wire-EDM etc. are used to fabricate micron parts and complex geometry features. Wet chemical etching is also an ancient and non-traditional method of having inherent advantages to produce micro feature, complex geometry, cost effective processes and minimum lead time, it is also known as photo chemical etching, photo-etching, photo chemical milling, photofabrication, photo chemical machining. In Wet Chemical machining material removal method is based on redox chemistry of etchant reduction affecting metal oxidation resulting in material dissolution with formation of soluble by-products that diffuse away from the reaction site. It produces burr free and stress free flat complex metal parts without affecting the material properties like hardness, ductility etc. Moreover the penetration rates of etching may be only $0.0005-0.0030 \mathrm{~mm} / \mathrm{min}$, but it is also necessary to find the deviation which takes place during the manufacturing of the specific geometry. The necessity to find the geometrical deviation is to aid the designer and the manufacturer to keep some allowance and tolerance in the pre-specified geometrical features to obtain the desired configuration. The application of wet etching machining includes in fields of automobile, aeronautics, aerospace, precise calibration instruments, food processing industries, electronics and semiconductor industries, medical sciences, and defence.

\subsection{Literature review}

Allen [1], have examined the art, roadmap, and newly-developed products by using PCM. Also, explained the relevant of Micro engineering, Micro fluids and Microsystems Technology, economic aspects and current challenges requiring research within the PCM industry. The PCM method of machining is compared with stamping, wire-EDM and laser machining and found that PCM can produce the same expected features as other methods.

B. Iyer, S. Nalbalwar and R. Pawade (Eds.)

ICCASP/ICMMD-2016. Advances in Intelligent Systems Research.

Vol. 137, Pp. 142-147.

(C) 2017. The authors - Published by Atlantis Press

This is an open access article under the CC BY-NC license (http://creativecommons.org/licens)es/by-nc/4.0/).

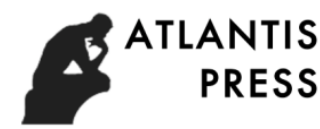


Zhang and Meng [2], have studied micro textures on carbon steel (ASTM 1020 steel) by using PCM. The micro textures include circles and right triangles with different sizes, prediction model of geometry of fabricated microtexture was proposed for etch depth less than 20 microns. Exposure time and development time mainly influence the precision of photo resist pattern. Experimentally it was found that the exposure time is independent of size and shape of profiles.

Cakir [3, 4], Copper etching with cupric chloride and regeneration of waste etchant was studied. Etchant concentration, additives and etching temperature were examined as an input parameter. $\mathrm{CuCl}_{2}$ provides high etch rate when compared with $\mathrm{FeCl}_{3}$ and produces less undercut. The copper dissolve capacity of $\mathrm{CuCl}_{2}$ is three times higher than $\mathrm{FeCl}_{3}$.

Cakir et al. [5] studied chemical etching of $\mathrm{Cu}-\mathrm{ETP}(99.90 \% \mathrm{Cu}, 0.005 \% \mathrm{~Pb}$ and $0.001 \% \mathrm{Bi}$, with high thermal conductivity and $55 \mathrm{HV}$ ) copper with two different etchants (ferric chloride and cupric chloride) at $50^{\circ} \mathrm{C}$. Copper dissolution capacity of $\mathrm{FeCl}_{3}$ is around $120 \mathrm{gm} / \mathrm{litre}$ and that of $\mathrm{CuCl}_{2}$ is $150 \mathrm{gm} / \mathrm{litre}$ in practical applications. $\mathrm{FeCl}_{3}$ produces more depth of etch and high etch rate then $\mathrm{CuCl}_{2}$, since $\mathrm{FeCl}_{3}$ etchant behaves like two etchant during machining as itself $\mathrm{FeCl}_{3}$ and etched by-product $\mathrm{CuCl}_{2}$. It was found that surface roughness decreases at the beginning of etching process and increase during etching process by $\mathrm{FeCl}_{3}$

Allen et al. [6], defines standards for industrial etchants (that are not chemically pure) and method by which they are analysed and monitored. The part dimension produced depends upon etch time and etchant composition, but the etching composition is continuously changing. Different monitoring parameters were defines and controlled. It was observed that if temperature is kept high the rate of etching will increase but its suggested to keep the temperature constant during etching process $\pm 0.5^{\circ} \mathrm{C}$ since etching is exothermic reaction and care should be taken to cool the etchant.

\subsection{Wet chemical machining process}

The Wet Chemical machining process has following advantages over traditional machining processes:

Requires no special tool

Short machining time

Economical machining cost

No plastic strain

High precision machining

Till date an accuracy of PCM depends only on the skill and experience of the operator. The main limitation of PCM is found in the characteristic of isotropic etching where etchant will not only act downwards but also act sideways beneath the photo resist. The detailed process layout is as shown in Figure 1. As the process has above mentioned benefits there is huge possibility to size and modify the batch products and their variety of configurations at a time, thus it is flexible in manufacturing aspect.

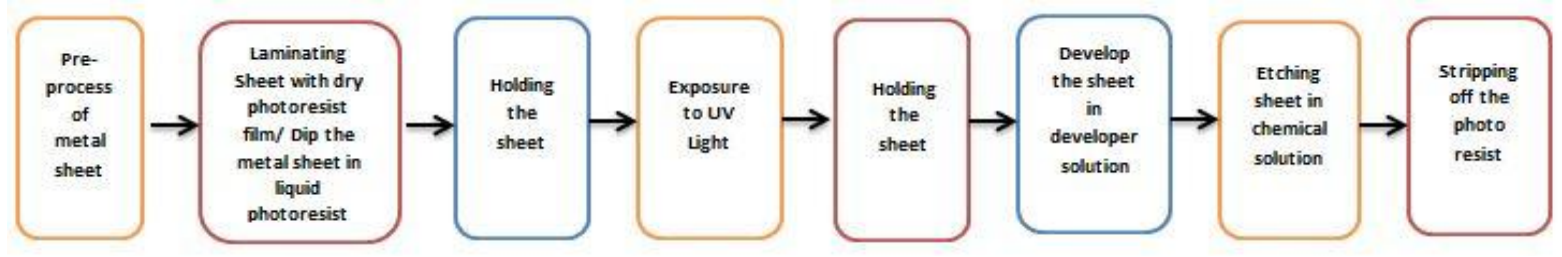

Fig. 1. Process flow diagram of Wet Etching

\subsection{Chemical Etchants}

The commonly used chemical etchants along with their properties are detailed in Table 1. In case of Ferric Chloride, the commonly used etchant for wet chemical machining the following reaction takes place,

$\mathrm{n} \mathrm{FeCl}_{3}+\mathrm{M} \rightarrow \mathrm{n} \mathrm{FeCl}_{2}+\mathrm{MCl}_{\mathrm{n}}$ 
In real time during the chemical reaction, the etchant concentration does not remain the same but it varies continuously. The etchant is consumed and by-product of ferrous chloride $(\mathrm{FeCl} 2)$ and metal chloride $(\mathrm{MCln})$ is produced.

Table 1 Properties of Etchants used for Wet Chemical Machining

\begin{tabular}{|c|c|c|c|c|c|c|}
\hline Etchant & $\begin{array}{c}\text { Applicable } \\
\text { to } \\
\text { Materials }\end{array}$ & Additive & Corrosive & $\begin{array}{c}\text { Neutralisation } \\
\text { and Disposal } \\
\text { Problems }\end{array}$ & Toxicity & $\begin{array}{c}\text { Operational } \\
\text { Cost }\end{array}$ \\
\hline $\begin{array}{c}\text { Acidified } \\
\text { Cupric } \\
\text { Chloride } \\
\text { (CuCl2) }\end{array}$ & $\begin{array}{c}\text { Beryllium copper, } \\
\text { Copper and alloys } \\
\text { including brass } \\
\text { and bronze, Lead }\end{array}$ & $\begin{array}{c}\text { Hydrochloric } \\
\text { acid }\end{array}$ & High & Low & Medium & Low \\
\hline $\begin{array}{c}\text { Acidified } \\
\text { Ferric } \\
\text { Chloride } \\
\text { (FeCl3) }\end{array}$ & $\begin{array}{c}\text { Aluminium, } \\
\text { Copper \& alloys, } \\
\text { Inconels, Invar, } \\
\text { Nickel, Phospher } \\
\text { bronze, Stainless } \\
\text { Steels, Tin. }\end{array}$ & $\begin{array}{c}\text { Hydrochloric } \\
\text { acid, Nitric } \\
\text { acid, Sodium } \\
\text { chloride }\end{array}$ & High & Medium & Low & Medium \\
\hline $\begin{array}{c}\text { Alkaline } \\
\text { Etchants }\end{array}$ & $\begin{array}{c}\text { Fabrication of } \\
\text { PCB }\end{array}$ & & High & Medium & Medium & High \\
\hline
\end{tabular}

\section{Experimental Work}

The orthogonal array experimental design technique proposed by Taguchi is used to study the parameters affecting the process, since the combined effect of parameters study is possible. The parameters used in chemical machining were etchant concentration, etching temperature, etching time. Design of Experiments (DOE) and Taguchi method of orthogonal array was used for three factors and three levels, which resulted in L27 array. Copper is selected as a sheet material for the experimentation. The products having complex and complicated shapes are selected and the attempt is being made to fabricate the geometrical complexity as close to desired ones. The objective of the paper is to find the geometrical deviation and measure it at three different stages throughout the machining process i.e. at the initial stage when the CAD model is being made, Secondly when the photo tool is printed, and lastly when the etched final product is fabricated. Thus, the geometrical deviation of the micro-texture feature can be analysed and studied to make necessary changes in obtaining desired configurations.

For measuring the geometrical deviation by wet chemical machining process the Flexure bearing and optical encoders are fabricated on copper sheet using Ferric Chloride solution as etchant. The flexure bearing and optical encoder's geometry has the complex and fine features. The deviations in case of circles, rectangles, etc. are studied.

Table 2 Classification of the experimental variables

\begin{tabular}{|l|l|l|l|}
\hline Process Parameters & $\begin{array}{l}\text { Response } \\
\text { Variables }\end{array}$ & Response Type & Unit \\
\hline Chemical Concentration & Undercut & Lower the better & $\mu \mathrm{m}$ \\
\hline Etching Temperature & Surface roughness & Lower the better & $\mu \mathrm{m}$ \\
\hline Etching Time & \multicolumn{2}{|l}{} \\
\hline
\end{tabular}

\section{Results and Discussion}

From the experiments it was observed that optimum parameters were etchant concentration 600 gm. /lit., etching temperature $54^{\circ} \mathrm{C}$, etching time of 14 minutes for one side etching. Experiments are carried out based on above method and the deviations are measured using optical microscope. The dimensions are measured at intermediate stages. 
In case of Flexure Bearing, the geometrical deviations of micro-texture include central hole and the slot width in the specimen geometry, whereas in optical encoders, the geometricaldeviation is measured with respect to central hole and peripheral rectangles. The graph is plotted to know the actual size produces from the specified CAD model.

Table 3 Slot width of flexure bearing

\begin{tabular}{|c|c|c|c|}
\hline Sr. No. & $\begin{array}{c}\text { CAD } \\
\text { MODEL }\end{array}$ & $\begin{array}{c}\text { PHOTO } \\
\text { TOOL }\end{array}$ & $\begin{array}{c}\text { ETCHED } \\
\text { PART }\end{array}$ \\
\hline 1. & 0.6 & 0.683 & 0.514 \\
\hline 2. & 0.6 & 0.66 & 0.491 \\
\hline 3. & 0.6 & 0.644 & 0.478 \\
\hline 4. & 0.6 & 0.629 & 0.438 \\
\hline 5. & 0.6 & 0.629 & 0.408 \\
\hline 6. & 0.6 & 0.618 & 0.385 \\
\hline Average & 0.6 & 0.6438 & 0.4523 \\
\hline
\end{tabular}

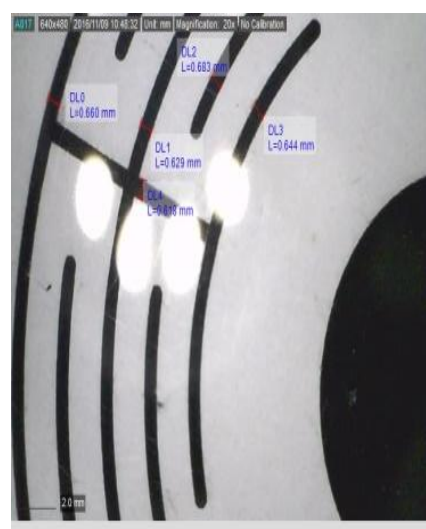

(a)

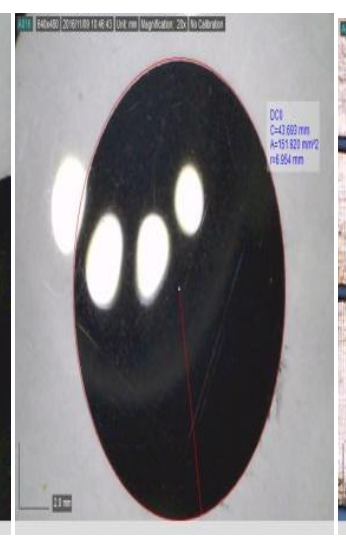

(b)

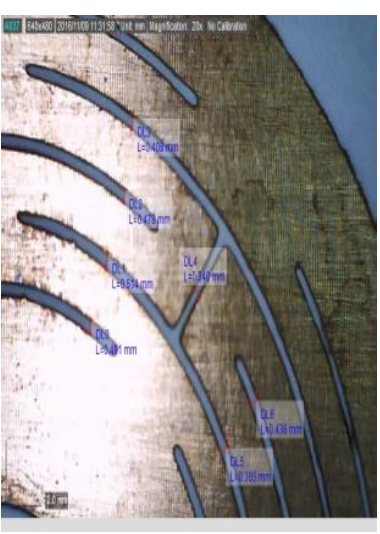

(c)
Table 4 Central hole deviation of flexure bearing

\begin{tabular}{|l|c|c|c|}
\hline Sr. No. & $\begin{array}{c}\text { CAD } \\
\text { MODEL } \\
\text { (MM) }\end{array}$ & $\begin{array}{c}\text { PHOTO } \\
\text { TOOL } \\
\text { (MM) }\end{array}$ & $\begin{array}{c}\text { ETCHED } \\
\text { PART } \\
\text { (MM) }\end{array}$ \\
\hline 1 & 6.85 & 6.954 & 6.832 \\
\hline
\end{tabular}

Fig. 2. Flexure Bearing, (a) \& (b) Photo tool and its measurement, (c) Etched specimen slot measurement,

(d) Etched central hole measurement

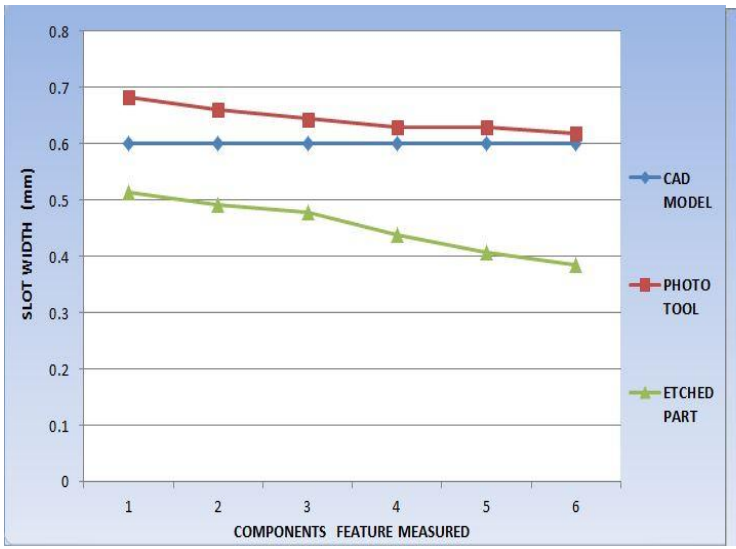

Fig. 3. Variation of Slot width Vs components measured

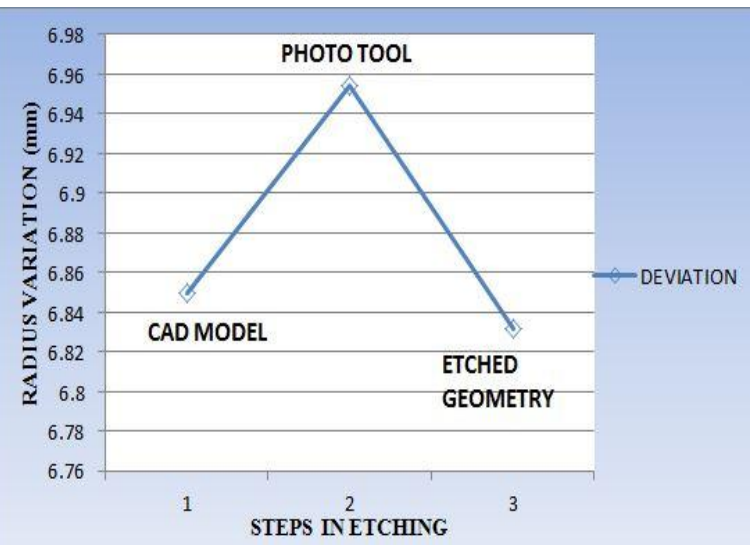

Fig. 4. Variation in radius of 1 central hole vs. steps in process 


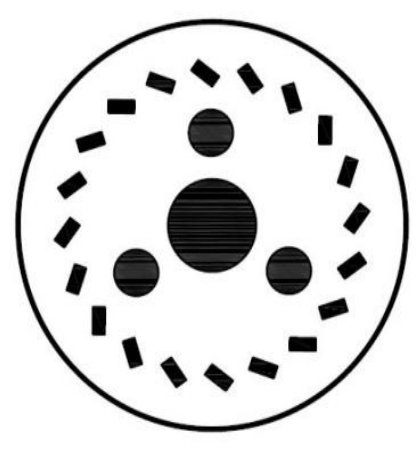

(a)

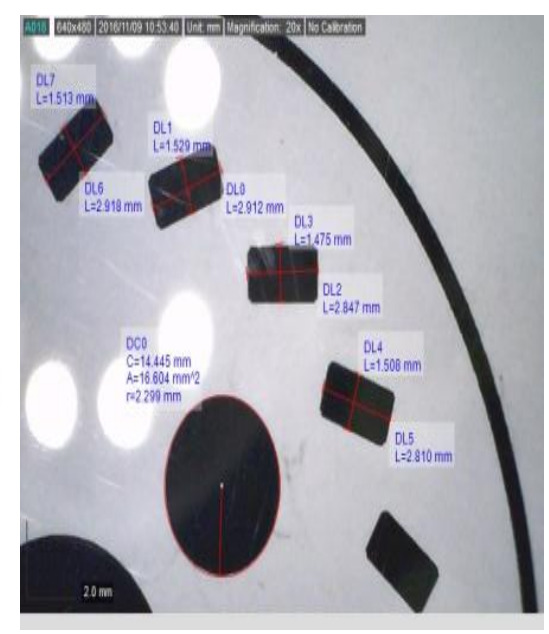

(b)

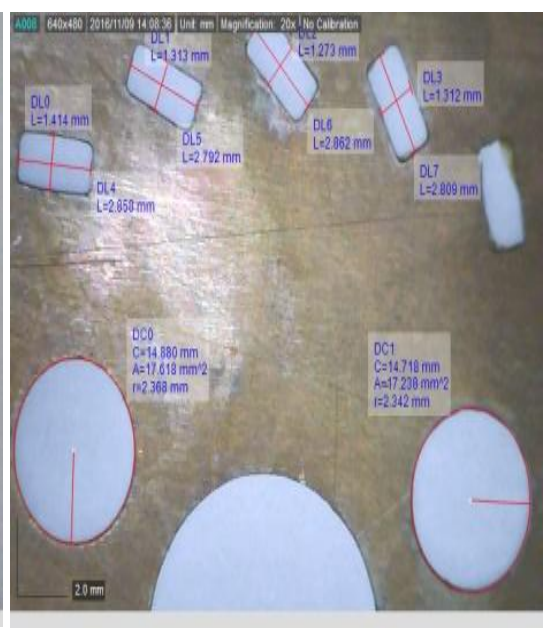

(c)

Fig. 5. Optical Encoders, (a) \& (b) Photo tool and its measured values, (c) Etched geometry and its measured values

Table 5 Geometrical deviation in rectangle of Optical encoders

\begin{tabular}{|c|c|c|c|c|c|c|c|c|c|}
\hline \multirow[t]{2}{*}{ Sr. No. } & \multicolumn{3}{|c|}{ CAD MODEL (mm) } & \multicolumn{3}{|c|}{ PHOTO TOOL $(\mathrm{mm})$} & \multicolumn{3}{|c|}{ ETCHED PART (mm) } \\
\hline & Length & Breadth & Area & Length & Breadth & Area & Length & Breadth & Area \\
\hline 1. & \multirow{9}{*}{2.951} & \multirow{9}{*}{1.360} & \multirow{9}{*}{4.0134} & 2.998 & 1.513 & 4.535974 & 2.858 & 1.414 & 4.041212 \\
\hline 2. & & & & 2.912 & 1.529 & 4.452448 & 2.892 & 1.394 & 4.031448 \\
\hline 3. & & & & 2.902 & 1.51 & 4.38202 & 2.864 & 1.373 & 3.932272 \\
\hline 4. & & & & 2.89 & 1.494 & 4.31766 & 2.82 & 1.383 & 3.90006 \\
\hline 5. & & & & 2.903 & 1.473 & 4.276119 & 2.808 & 1.34 & 3.76272 \\
\hline 6. & & & & 2.81 & 1.508 & 4.23748 & 2.764 & 1.337 & 3.695468 \\
\hline 7. & & & & 2.885 & 1.46 & 4.2121 & 2.809 & 1.312 & 3.685408 \\
\hline 8. & & & & 2.847 & 1.475 & 4.199325 & 2.792 & 1.313 & 3.665896 \\
\hline 9. & & & & 2.857 & 1.452 & 4.148364 & 2.862 & 1.273 & 3.643326 \\
\hline Average & & & 4.0134 & & & 4.3068 & & & 3.8175 \\
\hline
\end{tabular}

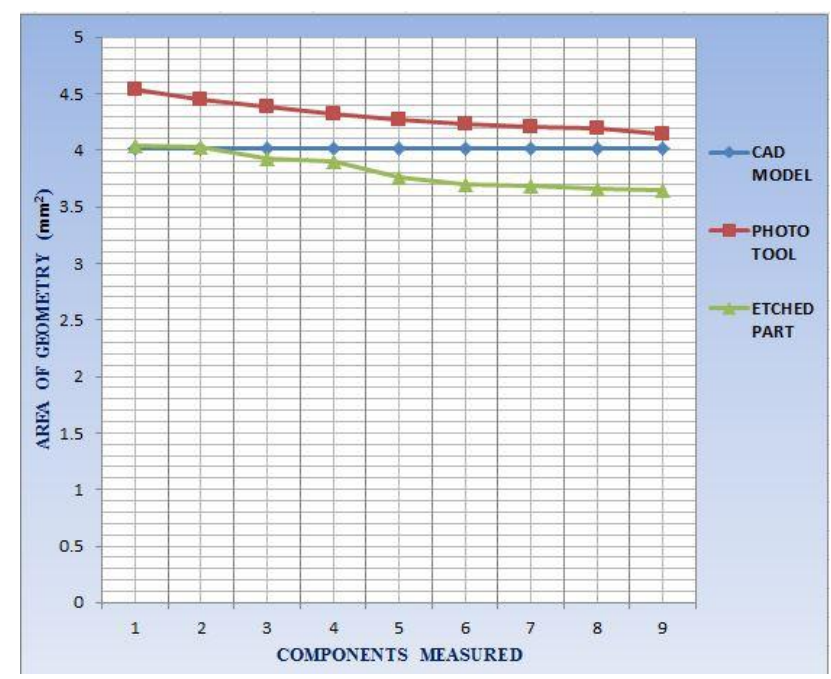

Fig. 6. Variation in rectangle area vs. components measured 


\section{Conclusions}

The experiments were completed on Copper sheet by using Ferric Chloride as an etchant at various temperatures. The observed important conclusions are enlisted below:

a) Ferric Chloride is most widely industrial accepted etchant and it results in reducing the weight of the specimen by etching the sheet.

b) It is observed that with increase in temperature of chemical and etching time it results in increase in depth of etch value. Also with increase in etching time the edges of the profile gets more etched evenly in normal direction of the sheet.

c) In terms of the geometrical deviations the intermediate measurement of the dimensions are made and noted. It has been found that the variation takes place in each stages of the process. The CAD model is prepared as per the desired specification but while printing the Photo tool the geometrical features are having variation of oversize, later after the exposure, development of sheet comes the etching where the etched dimension is found to be less than that of the CAD specified dimensions.

d) The average values of the rectangle area in case of Optical encoders and slot width in case of Flexure bearing are calculated from CAD Model, Photo tool and Etched part. The results obtained illustrates that the increased deviation of Photo tool with respect to CAD Model in Optical encoders and flexure bearings are $7.31 \%$ and $7.3 \%$ respectively, whereas the decreasing deviation of Etched part with respect to CAD Model in Optical encoders and flexure bearings are $4.88 \%$ and $24.62 \%$ respectively.

The future scope of the paper includes he attempts to minimize the deviations. Also, the causes of the deviation can be identified to achieve the desired outputs.

\section{Acknowledgement}

The authors would like to thank Prof.Dr.U.A.Dabade, Head of Mechanical Engineering Department, Walchand College of Engineering, Sangli, for providing the Photo Chemical Laboratory facility.

\section{References}

[1]. Allen D.M., "Photochemical Machining: from manufacturing's best kept secret' to a $\$ 6$ billion per annum", Rapid Manufacturing Process CIRP Annals, Manufacturing Technology, 53(2004) 559-572.

[2]. Zhang J, Meng Y, “A study of surface texturing of carbon steel by photochemical machining”, Journal of Materials Processing Technology, 212(2012) 2133-2140.

[3]. Cakir O., "Photochemical Machining of Engineering Materials", Trends in the Development of Machinery and Associated Technology, 12th International Research/Expert Conference, Istanbul, 2008.

[4]. Cakir O., "Copper etching with cupric chloride and regeneration of waste etchant", Journal of Materials Processing Technology, 175(2006) 63-68

[5]. Cakir O., Temel H., Kiyak M., "Chemical etching of Cu-ETP copper”, Journal of Materials Processing Technology, (2005) 275-279.

[6]. Allen D.M., Almond J.A., "Characterisation of aqueous ferric chloride etchants used in industrial photochemical machining", Journal of Materials Processing Technology, 149 (2004) 238-245.

[7]. Cakir O., "Chemical etching of aluminium", Journal of Materials Processing Technology, 99(2008) 337-340.

[8]. Roy R., Allen D.M., Zamora O, "Cost of photochemical machining”, Journal of Materials Processing Technology, 149(2004) 460-465. 